Cahiers $d u$ MONDE RUSSE

\section{Cahiers du monde russe}

Russie - Empire russe - Union soviétique et États indépendants

45/1-2 | 2004

Stratégies impériales

\title{
Les missions orthodoxes entre pouvoir tsariste et allogènes
}

Un exemple des ambiguités de la politique coloniale russe dans les steppes kazakhes

\section{Sébastien Peyrouse}

\section{(2) OpenEdition}

\section{Journals}

Édition électronique

URL : https://journals.openedition.org/monderusse/8680

DOI : 10.4000/monderusse. 8680

ISSN : $1777-5388$

Éditeur

Éditions de l'EHESS

\section{Édition imprimée}

Date de publication : 1 janvier 2004

Pagination : 109-136

ISBN : 2-7132-2008-4

ISSN : $1252-6576$

Référence électronique

Sébastien Peyrouse, "Les missions orthodoxes entre pouvoir tsariste et allogènes », Cahiers du monde russe [En ligne], 45/1-2 | 2004, mis en ligne le 01 janvier 2007, consulté le 03 septembre 2022 URL : http://journals.openedition.org/monderusse/8680; DOI : https://doi.org/10.4000/monderusse. 8680 
chercher : repérer : avancer

Cet article est disponible en ligne à l'adresse :

http://www.cairn.info/article.php?ID REVUE=CMR\&ID NUMPUBLIE=CMR 451\&ID ARTICLE=CMR 4510109

\title{
Les missions orthodoxes entre pouvoir tsariste et allogènes. Un exemple des ambiguïtés de la politique coloniale russe dans les steppes kazakhes par SÉBASTIEN PEYROUSE
}

\section{Editions de I'EHESS | Cahiers du monde russe}

\author{
2004/1-2 - Vol 45 \\ ISSN 1252-6576 | ISBN 2713220084 | pages 109 à 136
}

Pour citer cet article :

-PEYROUSE S., Les missions orthodoxes entre pouvoir tsariste et allogènes. Un exemple des ambiguïtés de la politique coloniale russe dans les steppes kazakhes, Cahiers du monde russe 2004/1-2, Vol 45, p. 109-136.

Distribution électronique Cairn pour les Editions de l'EHESS.

(C) Editions de l'EHESS. Tous droits réservés pour tous pays.

La reproduction ou représentation de cet article, notamment par photocopie, n'est autorisée que dans les limites des conditions générales d'utilisation du site ou, le cas échéant, des conditions générales de la licence souscrite par votre établissement. Toute autre reproduction ou représentation, en tout ou partie, sous quelque forme et de quelque manière que ce soit, est interdite sauf accord préalable et écrit de l'éditeur, en dehors des cas prévus par la législation en vigueur en France. Il est précisé que son stockage dans une base de données est également interdit. 


\section{LES MISSIONS ORTHODOXES ENTRE POUVOIR TSARISTE ET ALLOGÈNES}

\section{Un exemple des ambiguïtés de la politique coloniale russe dans les steppes kazakhes}

Au XIXe siècle, l'Église orthodoxe, institution affaiblie et dévalorisée aux yeux d'une partie des élites russes, tente de retrouver sa place en participant de manière intensive au processus de colonisation des steppes centrasiatiques. Elle joue là un double jeu, ne cherchant pas seulement à convertir des Kazakhs «païens» ou musulmans, mais également à raffermir son autorité sur les colons russes et surtout à s'affirmer face à l'État comme un partenaire incontournable dans son œuvre de russification des allogènes. L'histoire des missions orthodoxes dans le dernier tiers du XIXe siècle constitue donc une part, souvent ignorée, de l'histoire du monde kazakh et centrasiatique, mais également le moment d'une histoire proprement russe illustrant les difficiles relations Église-État dans les espaces colonisés.

La Russie s'est tournée vers les territoires asiatiques voisins dès la prise de Kazan en 1552. Les steppes bachkires sont conquises sous Pierre Irer, la Petite horde kazakhe se soumet en 1731 et devient un protectorat russe trois ans plus tard. Commence alors un inexorable processus de conquête des steppes que la Russie du $\mathrm{XVIII}^{\mathrm{e}}$ siècle oublie en partie, ayant d'autres préoccupations stratégiques ${ }^{1}$. Il faut attendre Nicolas Ier pour que le contrôle russe se renforce sur le territoire kazakh

1. Les forces russes sont en effet mobilisées par les événements en Crimée. Au XVIII ${ }^{e}$ siècle, Pierre le Grand privilégie une expansion vers la Baltique et la mer Noire afin de donner à la Russie une puissance maritime. Il s'oriente également vers le littoral occidental de la mer Caspienne (campagne contre la Perse en 1722-1723). La ville d'Azov perdue contre le khanat de Crimée lors de la guerre russo-ottomane (1711-1713) est reprise par l'impératrice Anne, laquelle pousse ses armées davantage vers l'ouest, en particulier vers la Prusse (Guerre de Sept ans, à partir de 1756). La deuxième moitié du XVIII ${ }^{\mathrm{e}}$ siècle est avant tout occupée par les deux guerres russo-turques (1768-1774 et 1787-1791). 
alors que, dans un même temps, les colons s'installent sur les terres nouvelles. Les Kazakhs, de tradition nomade, se soulèvent à plusieurs reprises contre cette culture sédentaire qui non seulement s'accapare les territoires sur lesquels ils transhument mais encore promeut une politique d'acculturation en les sédentarisant. La « pacification » en cours justifie une présence accrue de l'arsenal militaire tsariste : les lignes de fortifications russes s'enfoncent progressivement dans les steppes, ouvrent la route vers l'Inde, limitent la progression de la Grande-Bretagne en cette partie du monde et rehaussent à peu de frais le prestige de l'armée tsariste après la débâcle de Crimée².

Officielle et omniprésente dans la vie quotidienne, tant à la cour que parmi la population, l'Église n'en a pas moins essuyé des revers qui ont terni son image. Pierre le Grand ne l'a pas épargnée puisqu'il a procédé à l'abolition du patriarcat et imposé de très lourdes charges fiscales ; Catherine II a, quant à elle, entrepris la sécularisation des biens ecclésiastiques et son décret de 1764 a supprimé les quatre cinquièmes des monastères. La fin du XVIII ${ }^{\mathrm{e}}$ siècle octroie néanmoins à l'Église un renouveau tant dans le domaine spirituel que missionnaire. Constituant l'un des ferments et des piliers de la culture de la « Sainte Russie », l'Église suit attentivement la progression de l'armée tsariste : la colonisation est comprise comme un appel à la diffusion de la culture russe et du message biblique. Les colons russes ont toujours drainé dans leur sillage tant la foi que les traditions orthodoxes et l'Asie centrale ne fera pas exception. Cependant, la maîtrise de ces immenses zones steppiques supposera pour les orthodoxes une approche différente de celle qu'ils avaient pu envisager dans le cadre d'espaces sibériens très peu peuplés ${ }^{3}$.

Au-delà de la mission première de l'Église consistant à entretenir la foi de ses ouailles, les steppes kazakhes, peuplées de quelques millions de «non-chrétiens », se doivent de profiter du message biblique que l'Église s'évertue à diffuser. Celleci, privée de son indépendance, tente ainsi d'obtenir une nouvelle prise sur l'histoire en cherchant à participer à l'effort colonisateur des armées tsaristes. Tel est, au XIX ${ }^{\mathrm{e}}$ siècle, l'un des plus grands projets de l'Église orthodoxe que nous nous proposons d'aborder ici. Nous distinguerons dans une première phase les négociations que l'Église dut mener avec les autorités jusqu'à l'ouverture de la mission et les premières actions de celle-ci. Nous nous interrogerons ensuite sur son évolution après une première réforme en 1895, sur les nombreux problèmes qui résultent de l'évolution du contexte social des steppes kazakhes, ainsi que sur les obstacles que les missionnaires tenteront, avec peu de succès, de surmonter.

2. Cette défaite de la Russie en 1855, à l'issue de la guerre contre une coalition comprenant l'Angleterre, la France, la Turquie et la Sardaigne, a révélé les faiblesses internes d'un empire en apparence puissant, et entamé l'image d'invincibilité de l'armée russe.

3. Dans la seconde moitié du XIXe siècle, l'Église estime qu'un tiers des autochtones de Sibérie a déjà été converti par les prêtres de la mission de l'Altaï, voir « O missijah Tomskoj eparhii i Altajskoj-Kirgizskoj v 1882 godu » (Les missions du diocèse de Tomsk et de l'Altaï kirghiz en 1882), Tomskie eparhial'nye vedomosti, 8, 1883, p. 217. 


\section{I. Église orthodoxe et prosélytisme : les données d'une histoire ambiguë}

L'Église orthodoxe a longtemps nourri envers le prosélytisme des sentiments particuliers et hésitants. En effet, si le catholicisme a tenté de diffuser son message à l'échelle universelle, l'orthodoxie renvoie davantage à un schéma identitaire intérieur. Aux yeux de nombreux hiérarques, la foi chrétienne orthodoxe reste réservée aux populations slaves. Les « païens » doivent s'en tenir à leurs croyances et sont considérés comme indignes ou inaptes à recevoir la révélation chrétienne. Une telle approche n'est certes pas unanime mais elle prédominera longtemps, au moins dans la haute hiérarchie, limitant donc l'influence dont l'Église aurait pu disposer auprès d'une partie des peuples autochtones.

L'orthodoxie ne s'est pas pour autant désintéressée des nouveaux territoires ; néanmoins elle a préféré accompagner l'expansion plutôt que jouer un réel rôle missionnaire. Rappelons, pour symbole, l'entrée des troupes russes à Tachkent le 15 juin 1865 avec à leur tête un pope orthodoxe arborant la croix et soutenant la conquête au nom de la chrétienté 4 . L'Église sert en effet d'élément colonisateur de premier ordre puisque les communautés religieuses s'avèrent d'excellents pionniers en matière de défrichement des terres nouvelles. Elle étaye ainsi les desseins du tsar tout en poursuivant son propre objectif, perpétuer les valeurs chrétiennes au sein d'une population russe qui, coupée des paroisses, s'est en partie défaite des traditions religieuses. L'Église entretient de plus une certaine mystique à l'égard de la colonisation: l'idée d'un destin particulier de Moscou «troisième Rome» doit donner au reste du monde l'image d'un christianisme régénéré. Elle cautionne ainsi l'expansionnisme russe tout en s'octroyant une légitimité sur des territoires jusque-là ignorants des préceptes évangéliques ${ }^{5}$. Cette idée fut bien sûr exploitée par le pouvoir

4. Turkestanskij Kraj: Sbornik materialov dlja istorii ego zavoevanija (Le territoire du Turkestan : recueil de matériaux pour l'histoire de sa conquête), Tachkent, Izdanie Štaba Turkestanskogo Voennogo Okruga, 1914, XIX, part 1, p. 210 ; M. A. Terent'ev, Istorija zavoevanija Srednej Azii (Histoire de la conquête de l'Asie centrale), Saint-Pétersbourg, Tipo-Litografija V.V. Komarova, 1906, I, p. 315 ; cités in E. Allworth, ed., Central Asia, 130 years of Russian dominance. A historical overview, Durham - Londres, Duke University Press, 1994.

5. Les chrétiens font leurs premiers pas en Asie centrale dans la région de Merv avant le ve siècle. Melkites, Arméniens, Jacobites, mais surtout Nestoriens s'installent en Transoxiane probablement vers le viI ${ }^{\mathrm{e}}$ siècle et poursuivent leur développement sous la domination des Mongols. Ces derniers témoignent en effet d'une tolérance certaine à l'égard des religions du Livre. Tous ces mouvements sont cependant éradiqués de la région sous Tamerlan et ses successeurs, qui entreprennent une islamisation systématique, plus d'ailleurs dans un intérêt de stratégie politique que par réelles convictions religieuses. Au XIX ${ }^{\mathrm{e}}$, l'Asie centrale n'a pas été touchée par le christianisme depuis au moins trois siècles. Seuls quelques chrétiens ont réussi à pénétrer dans la zone, moins souvent dans un but missionnaire (Arthur Beylerian, « Deux lettres de Louis XIV au roi des Ouzbeks à propos de missionnaires jésuites », Cahiers du Monde russe et soviétique, IX, 2, 1968, p. 230-234) qu'informatif, tel que l'évêque grec Hrisanf à la fin du XVIII' siècle, voir C. Poujol, La Russie et l'Asie centrale, voyages et expéditions de 1700 à 1840, Thèse de troisième cycle, INALCO, 1985, p. 181-182 ; «Putešestvie mitropolita Hrisanfa po Srednej Azii i Tibetu v konce XVIII stoletija » (Voyage du métropolite Hrisanf en Asie centrale et au Tibet à la fin du XVIII ${ }^{\mathrm{e}}$ siècle), Turkestanskie eparhial'nye vedomosti, 1908, p. 266-275. Ces tentatives sont cependant vaines. Les quelques chrétiens présents dans la région sont des esclaves russes capturés et prisonniers dans les différents khanats. Ceux-ci n'ont aucun lieu officiel de culte et n'ont donc laissé aucune trace d'une présence tangible du christianisme dans la région. 
dès lors qu'elle put servir ses intérêts, en particulier à partir du règne de Nicolas ${ }^{\mathrm{e}}{ }^{\mathrm{e}}$, où fut mis en exergue le triptyque « orthodoxie, autocratie et génie national $»^{6}$.

L'activité proprement missionnaire de l'Église orthodoxe ne débute que sous le règne de Pierre le Grand, lorsque quelques prêtres tentent d'amener aux valeurs chrétiennes les autochtones du Grand Nord. Même si un archevêché existe en Sibérie dès 1621, les résultats ne sont guère probants : accompagnés de quelques soldats, les missionnaires apparaissent aux yeux des autochtones comme des agents de l'administration russe et non comme des apôtres de valeurs morales et spirituelles. Un Bureau des nouveaux convertis est créé en 1740 mais se voit fermé vingt-quatre ans plus tard par Catherine II, beaucoup plus tolérante envers les musulmans et moins bien disposée à l'égard de l'orthodoxie. L'Église conserve donc de nombreuses impressions en demi-teinte de ce premier prosélytisme. Si les peuples de Sibérie se soumettent rapidement mais superficiellement aux injonctions évangéliques, la christianisation des Tatars, majoritairement musulmans, laisse une âpre sensation d'échec. L'utilisation de moyens coercitifs donne en effet une maigre récolte : les enfants sont enrôlés de force dans les écoles et la volonté missionnaire prend souvent des allures de persécution massive ${ }^{7}$, entraînant de très vives réactions comme la participation des peuples de la région Volga-Oural à la révolte de Pugaščev ${ }^{8}$. D'autres troubles, en particulier chez les Bachkirs, conduisent les autorités tsaristes à imposer un certain nombre de restrictions en matière de prosélytisme : les missionnaires ne peuvent plus désormais exercer leurs talents sans l'accord du gouverneur local. Cette conversion rapide et superficielle entrâ̂nera par la suite une apostasie massive ${ }^{9}$, révélant ainsi la nécessité pour les orthodoxes de revoir leur stratégie missionnaire.

Le XIXe siècle connaît un certain regain missionnaire. Ce dernier n'a pas pour cadre unique l'Asie centrale mais s'inscrit au sein d'un renouveau général dans l'ensemble de l'empire russe : Makarij Gluharev choisit ainsi comme lieu de prédilection l'Altaï ${ }^{10}$, tandis qu'Inokentij Veljaminov (canonisé en 1977) implante de solides organisations missionnaires en Sibérie et évangélise les îles aléoutiennes ainsi que les Koriaks, Tchouktches, Iakoutes et Toungouzes ${ }^{11}$. L'Église ne cherche

6. Proclamée en 1833 par le ministre de l'Instruction publique, Uvarov, cette doctrine espère tant réaffirmer la cohésion nationale que justifier la mainmise sur les peuples conquis et le devoir de l'empire de les assimiler. Le triptyque confère par là même à l'empire sa base politique et spirituelle, sans pour autant affirmer une quelconque supériorité de l'ethnie russe, voir M.-P. Rey, De la Russie à l'Union soviétique : la construction de l'Empire (1462-1953), Paris, Hachette, 1994.

7. En 1756, une nouvelle loi décrète que les populations non chrétiennes doivent quitter toute ville dont $10 \%$ des habitants sont chrétiens.

8. F. T. McCarthy, « The Kazan` Missionary Congress », Cahiers du Monde russe et soviétique, XIV, 3, 1973,p. 313.

9. 11000 Tatars s'en retournent à l'islam en 1866.

10. N. Struve, «L'époque synodale 1721-1917», in D. M. Pospelovskij, Pravoslavnaja cerkov'v istorii Rusi, Rossii i SSSR (L'église orthodoxe dans l'histoire de la Rus', de la Russie et de l'URSS), Moscou, 1998, p. 73.

11. Ibid. 
plus à entreprendre quelques actions clairsemées sur l'immense territoire de l'empire, mais veut développer de manière systématique les missions, une volonté matérialisée par la création en 1870 d'une Société missionnaire orthodoxe censée coordonner l'ensemble des efforts ${ }^{12}$. Malgré les réticences d'une partie du clergé, l'Église se lance dans une nouvelle approche du missionnariat parmi les autochtones, en particulier turcophones : son projet est de dispenser une éducation chrétienne à des sujets baptisés mais peu enclins à suivre les préceptes bibliques en s'appuyant sur un enseignement dans les langues vernaculaires. Un nouveau système d'enseignement est élaboré en ce sens par Nikolaj Il'minskij. La même année, le Saint-Synode décrète l'interdiction de célébrer la liturgie aux autochtones dans une langue autre que la leur ${ }^{13}$. Ce réveil missionnaire paraît toutefois tardif au regard des actions conduites par les Églises catholique et protestante depuis plusieurs siècles et ce, d'autant plus que l'expansion russe a déjà un long passé.

\section{Une « mission kirghize anti-musulmane » dans les steppes : verses et controverses}

Au XIX ${ }^{\mathrm{e}}$ siècle, l'Asie centrale offre un nouveau cas de figure dans l'histoire des missions orthodoxes. Beaucoup plus peuplée que les grands espaces sibériens, la région est en outre de plus en plus soumise à un islam prêché par des mollahs tatars particulièrement actifs et efficaces ${ }^{14}$. Si les autorités gardent à l'esprit les revers du missionnariat orthodoxe dans la région Volga-Oural, l'Église entend poursuivre l'œuvre qu'elle a commencée plus au nord, consciente de la double tâche qu'elle s'impose : convertir au nom du Christ et russifier pour le bienfait de l'État, la première composante de ce leitmotiv justificateur cessant d'avoir un statut subalterne, comme il l'avait été aux XVII $-\mathrm{XVIII}^{\mathrm{e}}$ siècles. Cette approche n'évite néanmoins guère l'écueil d'un filtre russocentré : l'Église n'envisage aucunement d'instaurer un dialogue entre colons et colonisés et nul projet d'inculturation n'est suggéré, projet qui ne sera d'ailleurs proposé dans l'histoire missiologique qu'au $\mathrm{XX}^{\mathrm{e}}$ siècle : l'acculturation est et reste le maître mot. Le travail est donc immense, et lorsque les premiers prêtres se penchent sur les possibilités d'action, force est de constater qu'un long travail de préparation doit être envisagé avant même d'engager une quelconque action concrète. Leur méconnaissance de la région sera appréhendée et comblée d'un point de vue plus géographique et politique qu'anthropologique.

12. La Société missionnaire orthodoxe comptera jusqu'à 20000 membres. Dirigée par le métropolite de Moscou, elle est en partie financée par les cotisations annuelles de ses propres membres.

13. F. T. McCarthy, « The Kazan` Missionary Congress », art. cit.

14. Les Tatars de Kazan tentent de contrer la politique de russification (obrusenie ou rusifikacija) par leur prosélytisme en envoyant des missionnaires musulmans dans l'ensemble de l'empire russe. 
L'Église envisage d'exercer ses talents missionnaires dès la domination et la pacification des steppes par les Russes. Ainsi, en 1828, l'archevêque de Tobolsk souhaite fonder une première mission et envoie un jeune archimandrite afin de concrétiser ce projet. Un avis favorable est rendu à l'issue de cette prospection et une demande est adressée à la fin de l'année suivante au gouverneur général de Sibérie occidentale, I. A. Veljaminov, lequel opposera à ce projet une fin de nonrecevoir. Le refus de ce projet «prématuré », selon les termes du gouverneur ${ }^{15}$, reflète l'appréhension que nourrissent les autorités quant à un prosélytisme chrétien auprès des musulmans d'Asie centrale et, dans un même temps, le peu d'intérêt qu'elles manifestent quant à l'expansion de l'Église. Ce refus exprime surtout la crainte des autorités de voir leur pouvoir assimilé par les autochtones à une colonisation religieuse ${ }^{16}$. Trente années passent avant que les orthodoxes ne formulent une nouvelle requête en ce sens, déposée par le chef de la mission de l'Altaï, S. V. Landyšev. Les autorités espèrent alors clore définitivement le débat en invoquant cette fois une islamisation trop avancée pour que soit envisagée une mission chrétienne. Le gouverneur propose à l'Église d'envoyer une mission vers le lac Issyk-Kul, dans l'actuel Kirghizstan, alors occupé par les Chinois.

À la fin du XIX' siècle et au regard du contexte culturel des steppes kazakhes, les missionnaires envisagent trois niveaux d'approche : le premier est un travail régulier, mais somme toute assez semblable à celui qu'ils avaient mené auprès des peuples sibériens, à savoir une conversion rapide des populations chamanistes. Le second promet en revanche une approche plus complexe puisqu'il s'agit de travailler auprès des populations islamisées. Le troisième consiste à entretenir une foi et des valeurs chrétiennes auprès de personnes déjà converties mais que la distance géographique et surtout culturelle ont éloignées des valeurs orthodoxes. Il s'agit donc d'une action tous azimuts, tant au niveau de la population russe - cet aspect de la mission sera confié tantôt aux missionnaires, tantôt aux prêtres paroissiens - qu'auprès des autochtones. L'essentiel reste cependant un travail auprès des nouveaux convertis anciennement musulmans et une surveillance rigoureuse afin de ne pas renouveler les erreurs commises en pays tatar dans les années 1860 .

L'Église s'identifie au pouvoir colonial et s'efforce de convaincre ce dernier de l'attitude de défiance de la religion musulmane : elle insiste sur son caractère ambivalent, la présentant encore plus comme un mouvement politique que comme une religion. Brandissant le spectre du panturquisme et du panislamisme, elle martèle le danger d'une « tatarisation » depuis que Catherine II a favorisé les nombreux liens entre Tatars et Kazakhs et autorisé l'ouverture d'écoles tatares en territoire

15. «Kirgizskaja duhovnaja missija»(La mission spirituelle kirghize), Tobol'skie eparhial'nye vedomosti, 3 , février 1884, p. 50.

16. Des dissensions sur l'opportunité d'ouvrir une nouvelle mission dite « anti-musulmane » apparaissent au sein même de l'Église, certains craignant des réactions par trop hostiles des autochtones envers les missionnaires, voir « Pervoe prisoedinenie k pravoslavnoj cerkvi v Kirgizskoj missii Tobol'skoj eparhii » (la première conversion à l'Église orthodoxe dans la mission kirghize du diocèse de Tobolsk), Tobol'skie eparhial'nye vedomosti, 23, décembre 1894, p. 244. 
$\operatorname{kazakh}^{17}$. L'Église exploite pleinement cette «menace tatare », soulignant le rejet qu'elle suscite chez les Kazakhs mêmes : ces derniers n'ont-ils pas signé une pétition contre la présence tatare dès 1830 ? Elle fait également état du faible niveau de religiosité des Kazakhs. De fait, si l'islam a largement investi l'Asie centrale, la région n'est pas uniforme et plusieurs paliers d'islamisation se sont dessinés entre le sud et le nord. Les orthodoxes arguent ainsi que les populations kazakhes islamisées continuent à pratiquer un culte fortement teinté de pratiques chamanistes. Leur culture en matière religieuse reste très superficielle et peu de leurs membres sont par exemple à même d'expliquer la différence entre sunnisme et chiisme, d'autant plus que, malgré leur dynamisme, bon nombre de Tatars eux-mêmes ne sont pas au fait de tous les aspects de leur religion. Les cinq piliers de l'islam ne sont que peu observés, parfois pas du tout ; le pèlerinage à la Mecque est rarissime ; la régularité des prières n'est pas le premier souci des convertis, pour qui le nom d'Allah n'est parfois qu'une incantation ${ }^{18}$.

Il est donc encore possible, selon la hiérarchie, d'éviter le passage massif des Kazakhs à l'islam. L'Église se présente alors non seulement comme le défenseur des colons mais comme le protecteur de l'État russe contre le spectre musulman : mœurs et morale chrétiennes se conjuguent selon elle inéluctablement avec loyauté et déférence envers le régime tsariste. Les arguments du gouvernement seront beaucoup plus mesurés et réservés, du moins officiellement, quant au caractère ostentatoire à donner à une supposée supériorité russe sur les peuples colonisés. Jusqu'au XIX ${ }^{\mathrm{e}}$ siècle, la Russie a en effet pratiqué une politique qui alliait une volonté d'intégration à un respect plus ou moins officialisé des traditions et des coutumes des peuples rattachés à l'empire. Néanmoins, dans la deuxième moitié du siècle dernier, la montée d'un sentiment national ainsi que l'exaltation du génie russe et du panslavisme modifient les choix politiques : les autorités veulent s'assurer de la cohésion et de la docilité de leurs sujets. Cette politique menée sur l'ensemble du territoire impérial prend une ampleur nouvelle avec l'assassinat du tsar en 1881 et est perpétuée sous ses successeurs, Alexandre III et Nicolas II, par un proche de la cour, Konstantin Pobedonoscev, haut procureur du Saint-Synode de 1880 à 1905. Le pouvoir craint en effet des velléités séparatistes qui, selon lui, ne peuvent qu'être encouragées par une trop grande diversité nationale. Ce nationalisme officiel se confond rapidement avec l'exaltation de la foi orthodoxe et est suivi d'une politique de persécutions religieuses et de conversions forcées.

Cependant, le tsar, conscient de la diversité géographique de son empire, l'est tout autant de la diversité culturelle de ses sujets et ne croit pas en la possibilité d'une

17. Sous Catherine II, des écoles russes pour Kazakhs avaient déjà été ouvertes à Omsk et Orenbourg afin de former des interprètes, mais celles-ci manquaient de fonds et de personnel qualifié. L'impératrice autorisa alors la conduite de ces écoles par des religieux tatars, qui développèrent ainsi de manière officielle un sentiment religieux musulman parmi les élèves kazakhs. Les écoles militaires d'Omsk et d'Orenbourg, ouvertes respectivement en 1813 et 1825, ainsi que les corps cadets de Sibérie et d'Orenbourg, disposèrent également de classes spécifiques destinées aux Kazakhs.

18. Voir E. E. Bacon, Central Asians under Russian rule: A study in culture change, Ithaca, NY, Cornell University Press, 1966. 
politique unique en la matière. Ainsi, malgré l'islamisation superficielle des Kazakhs, les autorités restent prudentes vis-à-vis de ce peuple démographiquement beaucoup plus important que la plupart des autres allogènes et sur lequel les connaissances ethnologiques sont alors maigres. La méthode choisie consistera moins à russifier les autochtones via une orthodoxisation forcée qu'à tenter de faire venir en terre kazakhe un grand nombre de sujets russes et européens qui doivent contrer, voire submerger, tout effort ou ambition séparatiste et/ou nationaliste. Le pouvoir garde en effet à l'esprit la position géographique de cette région aux marges de l'empire : elle est non seulement une nouvelle ressource économique, mais également et surtout un lieu de passage inévitable vers le dominion britannique ${ }^{19}$.

La politique de Pobedonoscev trouve donc ses limites, et celles-ci sont aux portes de l'Asie centrale : la région est moins soumise aux atermoiements des décideurs et les représentants de l'empereur restent très circonspects envers l'idée missionnaire. Si l'Église estime que les relations sur ces nouveaux territoires s'expriment au travers du clivage religieux chrétien/musulman, le gouvernement conçoit un dialogue reposant sur une relation essentiellement politico-nationale, à savoir un dialogue Russe/Kazakh, colonisateur/colonisé. La christianisation des autochtones est donc jugée malvenue et les autorités l'exprimeront clairement à la hiérarchie religieuse puisque plus de soixante années de négociations seront nécessaires avant que le pouvoir n'autorise l'ouverture d'une première mission. Deux perceptions s'opposent au sein des autorités : certains entendent poursuivre le processus colonisateur d'un point de vue exclusivement administratif et économique, en respectant coutumes, traditions et religions des autochtones. À ceux-là s'opposent les partisans d'une lutte contre l'islamisation grandissante qui, selon eux, peut constituer une menace pour le pouvoir tsariste sur des territoires particulièrement étendus qu'il n'est pas en mesure de contrôler pleinement. Le seul moyen pour échapper à cette perspective serait alors de russifier les Kazakhs ou tout au moins de limiter le développement de l'islam.

La fluctuation des politiques gouvernementales permet donc à l'Église orthodoxe de formuler de nouvelles demandes, au moment précis où l'islam suscite de plus en plus d'inquiétudes. Ainsi, en 1881, l'évêque de Bijsk (Altaii) obtient enfin l'autorisation d'ouvrir une mission dite «anti-musulmane» dans les steppes kazakhes - Kirgizskaja ${ }^{20}$ protivomusul'manskaja missija. Les structures ecclésiastiques en territoire kazakh étant particulièrement faibles ${ }^{21}$, le Saint-Synode

19. La poussée russe vers le sud de l'Asie centrale dans la seconde moitié du XIX ${ }^{\mathrm{e}}$ siècle ainsi que la progression des possessions anglaises vers le bassin de l'Indus et de l'Afghanistan ont suscité de très vives tensions internationales. Deux traités entre la Russie et la Grande-Bretagne mettent un terme à ces frictions : le premier, signé en 1873 concernant l'Amou Daria, et le second signé en 1895 pour le Pamir, permettent de circonscrire la zone d'influence russe à Boukhara et de fixer les limites de l'empire britannique à l'Afghanistan.

20. Jusqu'au début du régime soviétique, l'administration russe nommera les Kazakhs « Kirghizes » et les Kirghizes « Kara-Kirghizes ».

21. Peu de prêtres sont présents dans la région par rapport à la population coloniale et l'Église ne dispose que d'un nombre réduit d'édifices religieux. Beaucoup de cultes sont célébrés dans des églises ambulantes qui suivent les armées russes au fil de leur progression sur ces territoires. 
place cette mission sous la direction du diocèse de Tomsk en Sibérie, l'un des principaux centres de la mission de l'Altaï créée en 1830. Celui-ci a fait ses preuves depuis de nombreuses années et bénéficie d'une solide expérience en matière missionnaire. Le gouvernement espère ainsi pouvoir limiter le développement de l'influence tatare dans la région, mais il garde une certaine réserve puisqu'il n'autorise dans un premier temps qu'une seule mission.

\section{Les difficiles premiers pas de la mission}

\section{Structure et organisation}

La mission de Tomsk connaît des débuts extrêmement modestes puisque l'autorisation accordée par les autorités ne sous-entend aucun soutien matériel et/ou financier. Elle est préparée par un prêtre formé de manière superficielle aux mœurs, aux coutumes et à la langue kazakhes mais c'est un autre clerc qui en assure les véritables débuts. Le premier centre, installé à Ust'-Kamenogorsk, a pour champ d'action l'oblast' de Semipalatinsk, suffisamment vaste si on en juge les moyens, tant humains que matériels, dont il dispose. Les fonds accordés par le diocèse de Sibérie sont eux aussi particulièrement modestes, celui-ci poursuivant dans un même temps son travail auprès des autochtones dans d'autres régions. Le missionnaire n'est d'autre part secondé que par une seule personne, un jeune Kalmouk formé au séminaire de Kazan.

Les deux missionnaires transfèrent par la suite leur centre dans le petit village de Bukon, à une vingtaine de kilomètres de Kokpektov ${ }^{22}$. Ils espèrent ainsi pouvoir prêcher dans trois oblasti, Semipalatinsk, Akmolinsk et Turgaj, et revendiquent l'ouverture d'autres missions. Les autorités répondent une fois de plus de manière mesurée : elles restent peu enclines à laisser se développer à grande échelle une mission orthodoxe, du moins tant que celle-ci n'aura pas apporté les preuves de son efficacité. En réalité, quelles que soient les opportunités administratives accordées, la mission ne peut avoir qu'un rayonnement modeste compte tenu de ses moyens. Plus de dix années de pourparlers seront donc nécessaires avant l'ouverture d'un nouveau centre missionnaire à Tobolsk en $1894^{23}$, qui prendra à sa charge l'oblast' d'Akmolinsk et une partie de celui de Semipalatinsk ${ }^{24}$. Enfin, un troisième sera

\section{Actuellement Kokpekti.}

23. L'évêché de Tobolsk a d'ailleurs revendiqué dès 1828 l'ouverture d'une mission dans les steppes kazakhes avant même que ne soit ouvert le centre missionnaire de Tomsk. L'ouverture de ce dernier donne de nouveaux espoirs au clergé orthodoxe de Tobolsk, qui formule de nouvelles demandes dès 1882. Sur la mission de Tobolsk, parmi les rapports écrits, on pourra consulter «Kirgizskaja protivomusul'manskaja missija tobol’skoj eparhii » (La mission antimusulmane du diocèse de Tobolsk), Tobol'skie eparhial'nye vedomosti, XV, 1894, p. 239-247 et XVI, 1894, p. 263-273.

24. «Otčet o dejatel'nosti Tobol'skogo eparhial'nogo pravoslavno-cerkovnogo bratstva Velikomučenika Dimitrija Solunskogo za 1893/4 god » (Compte rendu d'activité de la Fraternité orthodoxe du saint martyr Dimitrij Solunskij dans le diocèse de Tobolsk, 1893-1894), Tobol'skie eparhial'nye vedomosti, XXII, 1894, p. 241. 
ouvert à la même époque pour l'oblast' de Turgaj, rattaché cette fois-ci au diocèse d'Orenbourg 25 .

\section{Approche interculturelle et filtre russocentriste}

L'œuvre missionnaire que les orthodoxes se proposent de mener en Asie centrale est nouvelle à bien des égards. La découverte d'espaces et de peuples méconnus est l'incontournable clause du principe même de la mission, au-delà des nombreuses spécificités relatives au terrain d'action et au peuple convoité. Les orthodoxes doivent alors choisir et élaborer une «tactique d'approche» appropriée : de la perception réciproque dépend en partie le succès de la mission. Il importe surtout aux missionnaires de faire oublier les mauvais souvenirs de l'expérience tatare tout en proposant les mêmes objectifs, à savoir une conversion au christianisme, moins virulente cependant compte tenu de la politique restrictive imposée par les autorités. La présence tatare en Asie centrale, beaucoup plus réelle à la fin du XIX ${ }^{\mathrm{e}}$ siècle que précédemment, reste l'un des problèmes principaux des missionnaires : des récits tatars sur l'échec de la conversion forcée résulte sinon un ressentiment, du moins une réelle appréhension des Kazakhs à l'égard des colons et du personnel religieux. L'un des grands enjeux de la mission s'avère donc la capacité d'ouverture des missionnaires aux Kazakhs : comment instaurer entre soi-même et les populations à convertir, Kazakhs musulmans ou chamanistes, une relation reposant sur une différence religieuse, alors que les autorités tsaristes mettent sans cesse en exergue une relation fondée en premier lieu sur des bases économiques et politiques, et non sur une altérité religieuse ?

L'histoire des missions montre qu'un dialogue sur une double base chrétien/ musulman et colonisateur/colonisé est un classique de certaines politiques coloniales. La conjonction des deux n'est cependant pas une évidence et reste fonction d'une approche qui émane non de la direction religieuse mais des autorités : la politique coloniale tsariste dans la région étant ouvertement areligieuse, les steppes kazakhes n'entrent pas dans ce cas de figure. La liaison entre culture russe et orthodoxie et l'emprise que cette dernière exerce sur la conscience coloniale ont engendré une absolutisation de la religion, laquelle s'exprime avec d'autant plus de vigueur qu'elle est immergée dans un contexte socio-culturel méconnu. Cette idéologisation de la religion n'est certes pas le monopole de l'Église orthodoxe : dans l'histoire missiologique, catholiques et protestants ont bien souvent fondé leurs activités sur le postulat d'une inébranlable vérité et d'une indubitable supériorité. Les systèmes universels de signes et de symboles que sont devenus les deux religions, chrétienne et musulmane, se laissent donc interpréter et appliquer de manière différente, et peuvent tant légitimer un système oppressif que conduire à des expé-

25. A. Bennigsen, C. Lemercier-Quelquejay, « Musulmans et missions orthodoxes en Russie orientale avant 1917, Essai de bibliographie critique », Cahiers du Monde russe et soviétique, XIII, 1, 1972,p. 94. 
riences spirituelles intérieures hors du contrôle du pouvoir. Il résulte de cet état de fait différentes approches possibles, tant au niveau communautaire qu'individuel.

En cette fin du XIX ${ }^{e}$ siècle, l'heure n'est toutefois pas encore à une révision des procédés dans ce domaine. L'échange interculturel qui semble s'instaurer impose en réalité une relation unilatérale. Nul besoin de conjuguer relativisme culturel et absolu biblique : le second transcende ce qui est susceptible de contrevenir à l'unique vérité russe, chrétienne et orthodoxe. À l'instar de leur expérience sibérienne, les quelques missionnaires présents dans les steppes kazakhes refusent tous les prémices d'indigénisation de leur religion, la mission ayant un but non seulement religieux mais également « civilisateur ». Les orthodoxes ne peuvent accepter de concessions envers un peuple qu'ils considèrent comme proche de l'état sauvage. La perception des Kazakhs par les Russes reste en effet particulièrement empreinte d'ignorance et de parti pris : les nombreux rapports de prospection ou de mission témoignent de la piètre opinion que les missionnaires ont de ces peuples accusés de tous les maux et affublés de tous les adjectifs ${ }^{26}$. De leur côté, les Kazakhs ne saisissent pas toujours la fonction évangélisatrice des hommes d'Église et les assimilent à de simples colons, contribuant ainsi à porter à son paroxysme l'incompréhension entre les deux parties et poussant toujours plus loin un paradoxe dont ne peuvent se sortir les orthodoxes.

\section{Entre paternalisme, bienveillance et condescendance : les vecteurs missionnaires}

Dans cette perspective, les activités missionnaires auprès des catéchumènes sont empreintes de paternalisme. En tant que père spirituel et civilisateur, le missionnaire se doit d'éduquer ses sujets en les suivant pas à pas afin de les diriger, les soutenir, leur apprendre à mener une vie dans un esprit chrétien, mais également les punir s'ils dévient de la voie indiquée. Cette « rééducation » s'avère ardue compte tenu des objectifs orthodoxes et le pessimisme transparaît régulièrement dans leurs écrits : à plus long terme, une action efficace ne peut que s'appuyer sur une éducation des autochtones dès leur plus jeune âge. Plusieurs prêtres et missionnaires se penchent ainsi sur les moyens de faire entrer les autochtones dans le cadre culturel russe en élaborant des écoles et un système d'enseignement qui, tout en prenant en compte l'altérité culturelle de ces peuples, les formeraient dans le moule russe et en feraient des sujets convaincus du bien-fondé de la domination tsariste. Ces objectifs d'éducation des enfants autochtones ne sont pas nouveaux, ils avaient déjà été évoqués pour la Sibérie et les peuples musulmans de la Volga-Oural.

26. I. Belaev, Russkie missii na okrajnah. Istoriko-etnografičeskij očerk (Les missions russes à la périphérie. Étude historique et ethnographique), Saint-Pétersbourg, Sojkin, 1900, p. 25, 259260 ; «Zapiski kirgizskoj missii, svjaščennika Filareta Sin`kovskogo za poslednjuju tret’ leta 1882 goda (načalo kirgizskoj missii) i za 1883 god » (Mémoires du prêtre Filaret Sin’kovskij, missionnaire de la mission kirghize, pour le dernier tiers de 1882 (début de la mission khirghize) et pour 1883), Tomskie eparhial'nye vedomosti, 7, 1884, p. 1-28. 
Dans cette perspective de russification, plusieurs personnalités orthodoxes émergent et montrent un zèle tout particulier dans l'élaboration d'une réflexion sur les différentes méthodes d'enseignement possibles auprès des autochtones. La figure la plus éminente dans ce domaine sera Nikolaj I. Il'minskij. Si celui-ci s'intéresse à tous les peuples non orthodoxes, il attache une attention toute particulière à la conquête de l'Asie centrale. Il travaille d'ailleurs plusieurs années à la Commission d'Orenbourg, y apprend le kazakh et observe la montée de l'influence tatare. Ces longues années au contact des autochtones lui font acquérir l'intime conviction, à l'instar de bon nombre d'autres missionnaires, que les Kazakhs ne sont islamisés que très superficiellement: il faut donc les soustraire à l'influence des mollahs en les intégrant dans un système éducatif russe, sans pour autant les couper définitivement de leurs racines linguistiques et culturelles, ce qui ne ferait que les indisposer envers le nouveau régime.

Il'minskij se déclare en faveur d'un prosélytisme imprégné de conservatisme et de nationalisme russe ${ }^{27}$ et considère que la tâche principale du missionnariat consiste en l'éducation des autochtones, surtout musulmans, déclarés d'emblée hostiles aux projets tsaristes. Il organise pour cela un programme connu sous son nom qui consiste à conjuguer certaines méthodes d'éducation occidentales tout en leur donnant un esprit russe, le tout sur une charpente orthodoxe. L'enseignement doit cependant être dispensé dans les langues vernaculaires et par des professeurs autochtones. Il'minskij met d'autant plus l'accent sur la question linguistique qu'une confusion entre tatar et kazakh a jusque-là été perpétuée en Russie. Ainsi, des écoles russes pour Kazakhs ont été établies à Omsk et à Orenbourg, mais elles étaient généralement conduites par des Tatars. Constatant que ces écoles sont nuisibles aux intérêts tsaristes, des classes spéciales pour Kazakhs sont ouvertes; les élèves y sont formés dans leur propre langue afin de pouvoir ensuite entrer dans les administrations. Cependant, au-delà du système d'enseignement, la présence des Tatars dans l'administration des confins était telle que ceux-ci servaient généralement d'intermédiaire entre les Kazakhs et les Russes.

Afin de donner aux enfants leurs premiers contacts avec l'enseignement, des écoles d'aul-s qui suivent les transhumances des nomades sont également fondées. Elles connaissent néanmoins très vite une carence de professeurs : bon nombre d'entre eux fuient des conditions de vie difficiles et retournent dans les villes, peu ont par ailleurs reçu une formation spéciale. Le système proposé par Il'minskij sert donc tant les intérêts du pouvoir tsariste que ceux de l'Église orthodoxe ; il ne fait cependant pas l'unanimité au sein des autorités, surtout dans la mesure où ces expérimentations sont tributaires de la volonté des administrations locales. Beaucoup pensent en effet que les Kazakhs aspirent à étudier dans ces écoles dans l'unique but d'acquérir un prestige social. De plus, un maigre budget est alloué par le statut

27. Sur la vie et l'action de N. Il'minskij, on pourra consulter, entre autres, « Iz vospominanij o N. I. Il'minskom », (Souvenirs sur N. I. Il'minskij), Russkij vestnik, février 1892 ; N. I. Il'minskij, Izbrannye mesta iz pedagogičeskih sočinenij. Nekotorye svedenija o ego dejatel'nosti i o poslednih dnjah ego žizni (Pages choisies des œuvres pédagogiques. Aperçus de son activité et des derniers jours de sa vie), Kazan, 1892. 
de 1868 à l'éducation dans les steppes et octroie à ces nouveaux systèmes éducatifs peu de possibilités de développement : la centralisation du régime est telle qu'il est fait peu de cas des besoins et des nécessités des régions périphériques. Enfin, les finalités religieuses de ces écoles sont vite perçues par les autochtones, qui les accusent de véhiculer un prosélytisme chrétien, et cette crainte est reflétée par le refus de nombreux Kazakhs d'y envoyer leurs enfants. Les résultats, assez inégaux selon les oblasti, sont donc de manière générale relativement faibles ${ }^{28}$.

\section{Les obstacles : bilan d'un premier échec}

Les résultats d'une conversion des autochtones par écoles et professeurs interposés s'avèrent bien en deçà des espoirs qu'ont pu nourrir les orthodoxes. Une fois de plus, ils n'ont pu ou su convaincre tant la population visée que les autorités ; ces dernières ont montré, dans le meilleur des cas, une indifférence aux projets de l'Église et ont plutôt préconisé une soumission par la force politique et la cooptation des élites traditionnelles. Tant les moyens directs que les méthodes détournées n'ont donc apporté que de maigres fruits à la mission orthodoxe chez les Kazakhs.

Outre les tergiversations gouvernementales, d'autres obstacles sont venus joncher la route des steppes. Les longues hésitations du Saint-Synode quant au bien-fondé de cette mission ainsi que le peu de moyens consacrés témoignent d'un soutien particulièrement hésitant, et on peut légitimement s'interroger sur l'appui effectif de la hiérarchie orthodoxe elle-même. Cette dernière reste en effet, en cette fin du XIX ${ }^{e}$ siècle, sous l'étroit contrôle des instances étatiques. Si le Saint-Synode jouit de toutes les compétences en matière spirituelle, la présence d'un haut procureur représentant du tsar - monarque de droit divin - confirme que l'autorité émane avant tout de l'empereur. Le pouvoir décisionnel du Saint-Synode fait donc piètre figure et ne peut se départir d'une image ternie parmi les prêtres et missionnaires. Ceux qui sont présents dans les steppes montreront pour cette raison beaucoup de réserve dans leurs requêtes auprès du Saint-Synode et préféreront contourner son autorité en s'adressant à d'autres organismes tels que la Société missionnaire orthodoxe. Si celle-ci reste sous un étroit contrôle des autorités, ses intérêts et ses aspirations se rapprochent davantage des objectifs des missionnaires.

De plus, les quelques conversions que les missionnaires parviennent à obtenir ne sont pas sans poser de nombreux problèmes de compréhension interculturelle, à une époque où les ponts entre les deux populations restent particulièrement fragiles. La société kazakhe nomade, semi-nomade ou sédentaire, qu'elle soit chamaniste ou musulmane, considère le christianisme comme une foi coloniale, celle d'un envahisseur qui, depuis plus d'un siècle, lui subtilise ses terres et la contraint à adopter un nouveau mode de vie. D'autre part, si les Kazakhs ne sont pas des pratiquants fidèles de l'islam, la religion reste l'un des piliers de la

28. On compte 71 écoles pour 2000 élèves dans l'oblast' de Turgaj mais seulement 10 écoles pour 500 élèves dans celui d'Ural'sk. 
société traditionnelle : se convertir au christianisme constitue une double trahison, à savoir une auto-exclusion de ses pairs, un refus de la structure du groupe et de la responsabilité mutuelle qui en incombe, un rejet des liens parentaux et familiaux qui restent la charpente de l'édifice clanique kazakh. C'est également une entrée explicite dans l'univers des Russes et de leur pouvoir. Ainsi, les quelques baptêmes d'autochtones suscitent généralement des remous au sein du cercle familial du nouveau converti ; celui-ci est souvent contraint de se faire baptiser à l'abri d'indiscrets regards locaux; plusieurs d'entre eux ont été enlevés et ramenés de force dans les steppes, ce qui n'a fait que diminuer le nombre déjà restreint des acquis à la cause orthodoxe ${ }^{29}$. Le constat en ce milieu de la décennie 1890 campe donc sur un optimisme de façade teinté de doute, et les missionnaires aspirent à un certain nombre de réformes.

\section{De la restructuration à l'échec définitif}

Les maigres résultats obtenus par la mission ne sont reconnus qu'à mots couverts : journaux orthodoxes et revues missionnaires préfèrent mettre en valeur les quelques conversions obtenues ainsi que les contacts établis dans des villages kazakhs isolés. En 1895, plusieurs modifications sont néanmoins apportées à l'organisation des missions. Celles de Tomsk et de Tobolsk passent sous la responsabilité du diocèse d'Omsk, qui reçoit ainsi la charge des oblasti de Semipalatinsk et d'Akmolinsk. D'autre part, la responsabilité que ces missions font peser sur le diocèse de Sibérie et sur son centre missionnaire, éprouvé par des fonds et un soutien insuffisants, conduit la hiérarchie orthodoxe à créer deux entités distinctes, détachant la mission kirghize du diocèse de l'Altaï. Ces quelques réformes permettent de légitimer des ambitions que les missionnaires ne veulent aucunement reconsidérer en de plus modestes mesures.

La création de la mission d'Omsk doit permettre d'étayer l'action auprès des musulmans qui vivent dans les steppes en disposant d'un plus grand nombre de prêtres capables d'aller au devant des populations isolées. Elle a également pour but d'affermir le prosélytisme auprès des Kazakhs sédentarisés, prosélytisme qui jusque-là avait essentiellement contribué à ramener sur les bancs de l'Église des colons russes éloignés depuis parfois plusieurs décennies de l'orthodoxie. La mission de l'éparchie de Omsk ne comprend que sept stan-s - villages - divisés en deux catégories : les premiers, généralement composés de 10 à 35 foyers, sont essentiellement habités par des nouveaux convertis, ils disposent de leur propre direction agricole et sont sous la responsabilité permanente des missionnaires. La

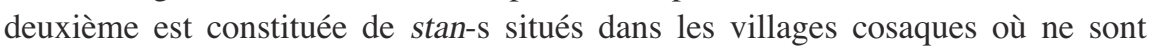

29. «Iz Semipalatinskoj oblasti » (Depuis l'oblast de Semipalatinsk), Tomskie eparhial'nye vedomosti, 1, 1887, p. 20. Ces enlèvements se perpétueront, et l'Église orthodoxe demandera officiellement aux autorités coloniales, en particulier lors du Congrès missionnaire de Kazan, d'y mettre un terme. Cf. «Kazanskij missionerskij s" ezd » (Le Congrès missionnaire de Kazan), Turkestanskie eparhial'nye vedomosti, 13, 1910,p. 304-305. 
regroupés que deux ou trois familles de nouveaux convertis ${ }^{30}$. Ces quelques modifications reposent avant tout sur un constat d'échec au regard de la décennie précédente. Si les Kazakhs ont été longtemps perçus comme peu et superficiellement soumis à l'islam, l'évolution du contexte socio-religieux en faveur de ce dernier au tournant du siècle semble, au mieux, rattraper les dispositions et les capacités des missionnaires et de leurs structures en Asie centrale, au pire, les devancer de plusieurs années, voire de quelques décennies.

\section{L'évolution du contexte socio-religieux en faveur de l'islam}

Le jeu entre les deux religions apparaît de plus en plus contrefait : depuis le début du siècle, l'islam a considérablement gagné en influence, largement véhiculé par les mollahs tatars, aidés parfois d'un clergé venu directement de l'Empire ottoman. Leur prosélytisme s'exerce de manière de plus en plus systématique, distançant ainsi, tant par leur nombre que leurs moyens, des missionnaires chrétiens déroutés. Présents selon les rapports des orthodoxes dans tous les aul-s, les mollahs peuvent exercer une influence de tous les instants. Ils jouent de leur proximité culturelle et linguistique et sont soutenus par les marchands tatars, considérés comme de virulents prosélytes et dont les mœurs, l'habit et la langue ne suscitent pas une prise de distance immédiate.

En cette fin de siècle, les réactions des orthodoxes gagnent donc en acuité face à une politique musulmane qu'ils perçoivent comme de plus en plus agressive ${ }^{31}$. Tentant de faire vibrer la corde nationaliste des autorités, les premiers accusent les seconds de diffuser des propos anti-russes et anti-chrétiens dans les ouvrages utilisés dans les medresses. Ces écoles musulmanes, qui ont connu au XIX ${ }^{\mathrm{e}}$ siècle un remarquable essor, restent l'une des cibles privilégiées des missionnaires. L'islam peut en effet être dispensé aux enfants dès leur plus jeune âge et ce, jusqu'à leur maturité dans les quelque 6300 écoles musulmanes recensées au Turkestan en 190032. En comparaison, les écoles russo-kazakhes ainsi que leur faible nombre d'élèves font piètre figure. Poussant la critique jusqu'au paradoxe, certains missionnaires reprochent même aux autorités d'avoir interdit les écoles tatares, ce qui aurait conduit les mollahs à partir enseigner directement dans les aul-s.

Face aux théories panturquistes et panislamistes qui commencent à rencontrer un certain écho en Asie centrale, l'inquiétude monte chez les orthodoxes. Ceux-ci

30. «O nuždah kirgizskoj protivomusul'manskoj missii omskoj eparhii i o nuždah eë pereorganizacii » (Au sujet des besoins de la mission kirghize anti-musulmane du diocèse d'Omsk, et sur la nécessité de sa réorganisation), Missionerskij s"ezd v gorode Kazani (Le Congrès missionnaire dans la ville de Kazan), Kazan, 1911.

31. « Pervoe prisoedinenie k pravoslavnoj cerkvi... », art. cit. p. 421-427 ; I. Belaev, op. cit., p. $274-280$.

32. Les orthodoxes considèrent que bon nombre d'écoles musulmanes sont ouvertes sans qu'aucune procédure administrative ne soit engagée. De fait, les autorités n'ont que des informations et des connaissances superficielles sur ces écoles et n'en ont inspecté qu'une minorité. 
s'érigent non seulement contre la conversion des «païens » à l'islam mais également contre un bloc musulman perçu comme une menace politique pour le monde russe. Dans ce contexte tendu, l'Église caresse le rêve de convaincre l'État de l'enjeu du prosélytisme. Une fois encore, les autorités restent insensibles à ces projets et ne sont pas sans savoir le très relatif développement des idées djadides ${ }^{33}$ parmi les nomades. Conscientes des risques d'instabilité que peuvent représenter les réformistes, elles optent pour une autre stratégie en vue de réduire leur influence en soutenant face à eux les conservateurs qadimistes. Ne pas froisser le camp choisi par un prosélytisme chrétien provocateur reste alors l'un des maîtres mots du pouvoir dans le cadre d'une politique du « diviser pour régner ».

\section{Perception des Kazakhs par les missionnaires et approche théologique}

Au-delà des réactions au prosélytisme musulman, la perception des Kazakhs par les prêtres orthodoxes reste toujours soumise au manque de connaissances et d'informations. Néanmoins, ces quelque vingt années de contacts ont permis aux missionnaires de s'estimer plus au fait de la culture et des usages du peuple kazakh. Si la progression de l'islam dans leurs rangs suscite inquiétude et suspicion, il est selon eux encore temps d'y remédier. L'optimisme reste donc de rigueur, du moins en apparence : l'activité des missionnaires musulmans n'a pu «corrompre » radicalement et en profondeur un peuple que l'on pense fermement attaché à ses traditions chamanistes ancestrales. Bien que convaincus de la superficialité de l'islam, les orthodoxes pensent que tout Kazakh est désormais susceptible de tomber dans son giron à court ou à moyen terme et que seule une sédentarisation sous la protection des Russes les y soustrairait.

L'appréhension des Kazakhs par les orthodoxes n'a cependant guère évolué et reste tissée de préjugés. Les missionnaires les accusent de tous les maux et ne tarissent pas d'adjectifs pour vilipender ce peuple que «la nature a doté de qualités négatives telles que la fainéantise, la malhonnêteté, l'esprit clanique (partijnost'), une fierté extrême », etc. ${ }^{34}$ Ce dénigrement dépasse la «licencieuse nature » de l'homme kazakh que les missionnaires avaient cru bon de dévoiler dans les rapports écrits des premières missions. Les quelques conversions qu'ils ont pu obtenir leur ont en effet révélé des allogènes peu motivés par le christianisme et surtout par la nécessaire présence aux offices. Empreinte tant d'ethnocentrisme que d'ignorance,

33. Courant musulman réformateur dont les idées sont élaborées principalement par un Tatar de Crimée, Ismail Bey Gaspiraly (1851-1914). Ce dernier, fortement influencé par les idées panslavistes, souhaite en transposer le principe dans le monde türk en unifiant les allogènes turcophones et musulmans de l'empire russe. Pour cela, il appelle à rénover l'islam par le contact avec le monde russe et l'Occident, à moderniser les sociétés tatare et centrasiatique par une série de réformes concernant les langues littéraires et le système scolaire. Le mouvement connaît un succès certain (plus de 5000 écoles djadides dans l'empire au début du siècle). Ce nouveau courant de pensée suscite une profonde scission au sein des Turco-musulmans sujets de la Russie entre les djadides et leurs opposants conservateurs dits qadimistes.

34. Missionerskij s"ezd v gorode Kazani, op. cit., p. 445. 
la perception des Kazakhs est donc désormais teintée d'un pessimisme sombre et les missionnaires semblent avoir perdu tout espoir de les doter d'une conscience religieuse et éthique chrétienne, même après le baptême.

D'autre part, si les confessions chrétiennes d'obédience protestante s'appliquent à rendre leur culte suffisamment clair et accessible, les orthodoxes font fi de toute simplification qui aurait «trahi » leur foi et rimé avec une démagogie protestante ou musulmane sur laquelle ils n'ont cessé de jeter l'opprobre. Ils s'en tiennent donc à une présentation complexe de la foi, opaque pour des novices peu motivés. Elle se traduit pour l'Église par une double concurrence tant des musulmans que des protestants qui, malgré l'interdiction qui leur est faite d'exercer de telles activités, parviennent parfois à leurs fins. Les orthodoxes inquiets s'en réfèrent, mais en vain, aux autorités coloniales ; certains tentent d'accentuer le caractère moral de l'orthodoxie et de simplifier les dogmes théologiques mais leur action ne fait pas l'objet d'un consensus au sein de la direction missionnaire.

De nouvelles tactiques d'approche de l'islam sont également envisagées : le missionnaire devrait avoir une connaissance approfondie non seulement des écrits religieux chrétiens mais également du Coran et de la religion musulmane. Le débat fluctue entre deux approches : certains missionnaires se montrent en faveur d'une confrontation plus ou moins directe avec l'islam, d'autres s'opposent à une critique qui froisserait plus qu'elle n'attirerait et n'apporterait pas les résultats escomptés. La confrontation orale face aux mollahs et aux musulmans convaincus que l'on envisage de convertir reste de toute façon difficilement réalisable, les moyens et les effectifs orthodoxes étant largement insuffisants. Les expressions anti-chrétiennes que perçoivent les missionnaires dans le Coran et la charia suscitent en outre de vifs débats sur la pertinence de laisser la loi musulmane gérer la vie kazakhe. Si, en effet, bon nombre considèrent que retirer la charia ne ferait que nourrir chez les allogènes des sentiments anti-russes, d'autres estiment qu'il faut s'interposer entre les autochtones et la loi musulmane en adaptant quelque peu aux principes locaux les règles de jugement imposées par les Russes. Cette question, évoquée dans le cadre de l'Église, fit également l'objet de longs débats au sein de l'administration coloniale ${ }^{35}$. Il s'en dégage cependant une certaine appréhension à attaquer de front l'institution islamique entière.

\section{De la christianisation à la russification : enjeux spirituels et socio-économiques}

La culture qu'ont apportée les Russes et les populations européennes n'est pas sans susciter l'intérêt ou tout au moins la curiosité de certains Kazakhs, en difficulté dans le cadre de conditions socio-économiques fluctuantes et incertaines. Si

35. V. Čeranskij, « Sudebnoe delo kirgizskogo naroda s religioznoj točki zrenija » (La législation du peuple kirghiz d'un point de vue religieux), Sotrudnik, 22-23, 1910. Membre du Conseil d'État, l'auteur déclare que la charia est dénuée de respect envers les non-musulmans et ne peut en aucun cas régir la vie des Kazakhs. Afin de contrer son influence, les Russes se doivent d'adapter leur législation aux besoins et aux conceptions kazakhs. 
l'orthodoxie peut être péjorativement connotée par une population qui condamne la colonisation russe et ses méfaits, elle apparaît parfois comme un premier pas vers un monde que d'aucuns envient. Les conditions de vie des nouveaux convertis restent cependant bien en deçà de ce qu'ils avaient espéré ; mais en ce tournant de siècle où la situation d'une très grande majorité de Kazakhs ne cesse de se détériorer, toute opportunité est envisagée. Le baptême devient ainsi une aspiration au paraître. Malgré les difficultés qu'ils connaissent, les Russes jouissent d'un statut privilégié et l'orthodoxie apparaît comme l'un des emblèmes du colonisateur : s'y convertir permet d'espérer une ascension sociale et un soutien matériel.

Cette idée est d'autant plus véhiculée que le gouvernement tsariste octroie, dans l'espoir d'une russification des allogènes, des prêts pour tout autochtone nouvellement baptisé afin de favoriser sa sédentarisation. Les rapports mettent en exergue cet aspect matériel de la mission, que de nombreux prêtres ont ensuite été accusés d'avoir privilégié aux dépens de l'aspect spirituel de leur fonction. La christianisation des Kazakhs suppose pour les orthodoxes leur sédentarisation. Les missionnaires doivent ainsi aider les convertis à se défaire de leur mode de vie nomade en assurant un suivi religieux mais aussi économique et social. Cette transition suppose cependant de leur fournir une surface minimale de terres alors que les conditions du tournant de siècle ne s'y prêtent guère : trouver des terres devient d'année en année plus laborieux. Si la colonisation paysanne s'opère lentement dans un premier temps et est étroitement contrôlée par la Commission des steppes jusque dans les années 80, elle s'accélère à partir de 1889, l'État étant de plus en plus préoccupé par la crise agraire qui sévit en Russie centrale et méridionale. Les paysans russes, qui ont commencé à s'installer dans les steppes dès les années 1860, affluent tout particulièrement pendant la famine de 1891$1892^{36}$. Profitant des privilèges de leur statut de colons, ils s'accaparent de grandes superficies de terres parmi les plus fertiles. Cette prise de possession des pâturages est d'ailleurs l'un des motifs principaux de friction entre Kazakhs et colons russes ${ }^{37}$.

L'État encourage de plus en plus les départs en direction du Gouvernement général des steppes et, en 1910, ouvre officiellement le Turkestan aux colons. Les conséquences humaines et économiques en sont particulièrement importantes ${ }^{38}$ : alors que les colons ne constituent qu'un dixième de la population du Semireč'e, ils disposent d'une large majorité des terres cultivables et aspirent à mettre en valeur la région. Il en résulte une paupérisation des Kazakhs dont bon nombre sont contraints

36. Cet afflux a d'ailleurs été suscité et officialisé par une loi promulguée en juillet 1889, laquelle a permis à chaque paysan russe d'être candidat à un déplacement dans les steppes. Cette loi entre dans le cadre d'un peuplement européen rural de grande ampleur, voir V. Fourniau, Histoire de l'Asie centrale, Paris, PUF, coll. Que Sais-je ?, 1994, 127 p.

37. Et ce, jusqu'à la collectivisation en 1928, date à laquelle la propriété privée est abrogée. Les Kazakhs ne peuvent alors plus revendiquer des terres désormais nationalisées.

38. Alors que le nombre de colons russes installés en Asie centrale plus ou moins légalement en 1896 est estimé à 400 000, leur nombre atteint un million et demi entre 1896 et 1916, ce qui représente un tiers des départs enregistrés vers la partie asiatique de l'empire. Sur la colonisation de l'Asie centrale, voir M.-P. Rey, De la Russie à l'Union soviétique, op. cit. 
de se sédentariser pour subsister. Les mauvaises récoltes provoquées par la sécheresse de 1890-189139 aggravent la situation des nouveaux sédentarisés. D’autre part, posséder une terre ne signifie pas avoir les moyens matériels et financiers suffisants pour l'exploiter. Le prix du sol et des animaux est devenu inabordable et la mission ne dispose pas des moyens nécessaires pour en payer le bail.

Cette déstabilisation est d'autant plus durement ressentie par les Kazakhs convertis au christianisme qu'ils auraient pu poursuivre leur vie nomade ou seminomade, au moins provisoirement. La conversion au christianisme ayant été considérée par leurs proches comme une trahison, les Kazakhs chrétiens se trouvent exclus d'un jeu social fortement structuré. Il incombe donc aux missionnaires d'établir de nouvelles structures d'encadrement pour ces «marginaux ». L'isolement des quelques convertis ainsi que les effectifs particulièrement restreints des missionnaires entravent pourtant l'élaboration d'un réseau de relations solides entre les nouveaux convertis kazakhs, les religieux et les pratiquants russes. Les quelques villages fondés par l'Église pour les convertis afin de regrouper moyens et forces sous son propre contrôle ne résolvent en effet ni le manque de terres ni l'absence de moyens plus conséquents pour leur assurer le niveau de vie nécessaire. Nombre d'entre eux apostasient et s'en retournent dans les steppes.

\section{Missions chrétiennes et autorités coloniales : divergences et interférences}

\section{La loi de tolérance religieuse}

L'évolution du contexte politique au début du $\mathrm{XX}^{\mathrm{e}}$ siècle ne joue pas en faveur des missionnaires et, de manière plus générale, du christianisme en zone musulmane. En 1905 est en effet adoptée une loi de tolérance accordant à chacun la liberté de religion ainsi que le droit de se convertir à celle de son choix. Cette nouvelle législation révèle la face cachée de la religion dans l'empire tsariste : au lendemain de son adoption, des milliers de personnes officieusement converties à l'islam le déclarent officiellement ; 50000 autres personnes font le choix de l'embrasser immédiatement ${ }^{40}$. Les missionnaires ressentent cette loi d'autant plus durement qu'elle permet aux religieux musulmans d'exercer de manière désormais ouverte une action autrefois seulement tolérée. Leur ressentiment à l'égard du gouvernement est vif ; ce dernier est accusé de vouloir limiter le prosélytisme orthodoxe sans dresser le moindre obstacle à la montée d'une influence musulmane qui œuvrerait contre les intérêts de l'État russe. Outre l'islam, les mouvements chrétiens dits « sectaires », en particulier d'obédience protestante, deviennent également de nouveaux concurrents officiels puisqu'ils ont désormais tout le loisir de convertir

39. M. B. Olcott, The Kazakhs, Stanford, Hoover Institution, Stanford University, 1987.

40. Cf. Pravoslavnyj blagovestnik, 2, 1909, p. 412. 
tant les musulmans que les chrétiens orthodoxes ${ }^{41}$. Le choc vient donc de toutes parts et dans les rangs des religieux circule de plus en plus l'idée qu'il ne faut plus s'en remettre aux décisions bureaucratiques, mais agir sur sa propre initiative. La loi de 1905 témoigne en effet d'une sollicitude de plus en plus distante des autorités à l'égard des objectifs orthodoxes, dont l'échec a fini par désintéresser le pouvoir de leur sort.

Si Nikolaj Il'minskij avait réussi à convaincre les autorités que les différences entre Russes et autochtones étaient si marquées que ces peuples ne pourraient fusionner sur des bases uniquement politiques, l'ordre du jour gouvernemental est désormais différent et l'influence que pouvait exercer Il'minskij en son temps est révolue, au moins en matière de prosélytisme. Toutefois, au-delà de finalités communes, les avis divergent de manière radicale sur les méthodes à appliquer dans le cadre d'une mission qui, en 1910, reste très centralisée. Le procureur général conserve un pouvoir absolu sur l'Église orthodoxe et les quelques revendications pour conférer aux instances missionnaires plus de droits et d'indépendance restent vaines. Quelques réformes sont proposées dans le but d'anesthésier un clergé contestataire que l'échec conduit à émettre des revendications tous azimuts. Un Concile missionnaire de toutes les Russies chargé de coordonner l'activité missionnaire est ainsi créé en 1913 mais il n'entraîne aucun changement notable pour la mission dans les steppes kazakhes. Les nombreuses demandes formulées par les missionnaires afin de limiter les droits du prosélytisme musulman - interdire aux Tatars d'employer certains mots dans les journaux tels que «non-croyants » ou « impurs », demander au pouvoir législatif d'exercer une pression morale sur les personnes qui envisagent d'apostasier — restent lettre morte. La colère de Dieu et la condamnation éternelle que promettent les orthodoxes à tout contrevenant à la morale chrétienne arrivent fort mal à propos à une époque où les autorités sont beaucoup plus préoccupées par les troubles sociaux que par des questions religieuses.

\section{Des difficultés matérielles accrues}

Ces difficultés politiques sont d'autant plus durement ressenties que les conditions de développement de la mission dans la région sont difficiles. Chaque missionnaire se retrouve en charge d'un territoire toujours plus grand qu'il ne peut en aucun cas assumer. Tant les moyens matériels pour parcourir ces immenses superficies que les effectifs humains manquent. Les quelques voyages que les prêtres entrepren-

41. Depuis la fin du XIX ${ }^{\mathrm{e}}$ siècle, la migration des populations européennes a drainé dans son sillage de nombreux membres de mouvements d'obédience protestante tels que les baptistes, les adventistes du septième jour, les mennonites, pentecôtistes ou encore deux petites communautés de témoins de Jéhovah. Il faut également ajouter les mouvements d'origine russe tels que les vieux-croyants et les molokans, particulièrement bien représentés aux marges de l'empire (voir : «Molokanstvo v Turkestane rastët » (La communauté des molokans croît au Turkestan), Turkestanskie eparhial'nye vedomosti, 19, 1908, p.625-626; «Sektanty v Turkestane » (Les sectateurs au Turkestan), ibid., 17, 1910, p. 377-378; « Baptizm i sposoby ego propagandy » (Le baptisme et ses moyens de propagande), ibid, 23, 1910, p. 505-510). 
nent dans les steppes aux alentours de leur village n'excèdent pas deux ou trois mois par an et les conditions dans lesquelles ils sont réalisés n'offrent aucune possibilité sérieuse de prosélytisme. Surchargés par les tâches administratives ainsi que par les charges paroissiales quotidiennes, les missionnaires ne disposent pas du temps nécessaire pour se consacrer à leur activité première. Ceux qui résident dans les villages constitués pour les nouveaux convertis sont de plus contraints de consacrer une grande part de leur temps à des questions d'organisation.

En outre, les maigres résultats obtenus ont cessé de convaincre les quelques membres du gouvernement favorables à la mission orthodoxe d'apporter à cette dernière une aide qui, de toute façon, n'a jamais été substantielle. Les sommes allouées diminuent ainsi de plusieurs milliers de roubles chaque année ${ }^{42}$. Cette baisse est d'autant plus notable pour les missions que, nous l'avons vu, les Kazakhs se tournent souvent vers les religieux dans l'espoir d'accéder à un statut social plus élevé. Au-delà de l'image de déchéance qu'elles donnent, les missions n'ont pas non plus les moyens de promouvoir leurs idées par différents livres et écrits religieux qui demanderaient un investissement conséquent. Aucun des projets de publications, en particulier d'ouvrages traduits en kazakh expliquant dans une perspective chrétienne le Coran, n'a par exemple vu le jour.

\section{Désintérêt des Russes et démobilisation du clergé paroissial}

Si la mission orthodoxe offre une image ambiguë aux yeux des autochtones, elle n'apparaît pas non plus sous son meilleur jour pour la population russe et le clergé paroissial, et souffre de vives critiques. Ses fins ultimes sont mises en cause et souvent mal acceptées compte tenu des investissements financiers, matériels et humains nécessaires à son existence, qui revêtent pour beaucoup un aspect fictif. Cette indifférence glisse souvent vers une franche hostilité à l'égard des missionnaires, renforçant le sentiment d'isolement de ces derniers. Les conflits entre missionnaires et paroissiens sont d'autant plus fréquents que leurs relations ne sont soumises à aucun règlement écrit. De son côté, la population laïque russe nourrit à l'égard des Kazakhs une appréhension mêlée d'hostilité et reste sceptique quant à leur possible russification. En s'installant sur ces nouveaux territoires, les colons, immigrés économiques avant tout, ne se jugent pas particulièrement menacés par la population autochtone et par sa religion.

Un réel sentiment d'insécurité ne se fait vraiment sentir qu'à l'aube du siècle lorsque les Kazakhs, excédés par les confiscations sans fin de leurs pâturages et écrasés par les conditions économiques, forment des groupes armés et attaquent régulièrement les cadres administratifs russes mais aussi les propriétaires de grandes terres agricoles. Jusque-là, nul besoin n'est ressenti par les colons mêmes de russifier ces peuples. L’orthodoxie apparaît comme réservée aux peuples 
slaves ; cette idée est d'autant plus présente que l'ethnocentrisme des colons et leur mépris des autochtones sont exacerbés sur ces territoires par leur effectif minoritaire et l'éloignement de leurs terres d'origine. Ce sentiment d'appartenance nationale et de communautarisme est d'ailleurs au moins aussi développé que l'aspect strictement religieux et spirituel de l'orthodoxie, la conscience théologique des colons restant souvent, au grand dam des prêtres, relativement faible. Il s'avère alors difficile de convaincre ces derniers de l'utilité et du bienfait de la morale orthodoxe pour les Kazakhs. Ceux-ci doivent s'en tenir à leur religion et/ou à leurs pratiques coutumières et le clivage entre peuple colonisateur et peuple colonisé subsiste : pour les colons russes, un Kazakh naît chamaniste ou musulman et doit le demeurer. L'appel à l'aide adressé par les missionnaires aux laïques russes est ainsi resté vain et s'est même souvent soldé par une franche opposition.

\section{Vers une réforme de la fonction de missionnaire?}

Les remises en cause de l'activité missionnaire viennent de toutes parts et chacun tente d'apporter - ou de retirer - sa pierre à un édifice déjà moribond. La question première et essentielle, conséquence des problèmes évoqués, est la redéfinition de la fonction même du missionnaire. Cette fonction est de moins en moins reconnue en Asie centrale et elle est de toute façon mal définie, compte tenu du caractère rudimentaire des premières installations. Il faut donc, selon les religieux, redistribuer les cartes, impartir et garantir aux missionnaires des fonctions précises qui leur laisseraient tout le loisir d'accomplir leur tâche. Leurs activités se superposent en effet à celle des prêtres paroissiens et les dissensions entre ces deux corps d'Église sont fréquentes. L'activité des premiers est de plus en plus remise en cause par les seconds, beaucoup estimant que les résultats de la mission sont minimes depuis sa séparation de celle de l'Altaï en 1895 : les quelques conversions recensées émanent en réalité de Kazakhs sédentarisés vivant au contact des Russes depuis de longues années. Des demandes en vue de séparer les deux fonctions sont donc régulièrement faites afin d'officialiser le rôle du missionnaire aux yeux de tous.

Pour les missionnaires, l'obligation de demander l'autorisation au chef de l'éparchie pour baptiser un autochtone doit être abrogée car elle entrave une activité déjà faible, qui s'inscrit en outre dans un contexte de discorde entre les deux fonctions, celle de missionnaire et celle de prêtre. Le chef de la mission devrait devenir indépendant dans le choix de ses collaborateurs ${ }^{43}$. Les missionnaires devraient être libérés de leurs charges paroissiales, laissées de manière exclusive aux prêtres

43. Il est demandé au Congrès de Kazan de faire du chef de la mission et des missionnaires des membres à part entière du comité éparchique de la Société missionnaire, avec droit de vote, à l'instar des membres du comité. L'ancien statut, rédigé un demi-siècle plus tôt par l'évêque Vladimir de Bijsk alors que seule la mission de l'Altaï existait, ne faisait pas des missionnaires des membres à part entière et ils ne pouvaient pas donner leur avis lors des décisions relatives aux affaires de la mission prises par le comité, voir Missionerskij s"ezd v gorode Kazani, op. cit. 
paroissiens, ainsi que de toute charge familiale; à ce titre il sera suggéré de n'employer que des moines. On escompte ainsi faire des missionnaires des spécialistes du prosélytisme et leur proposer un cadre de formation spécifique, tant pour leur fonction que pour la zone géographique dans laquelle ils sont envoyés. Des cercles missionnaires devraient être formés dans chaque paroisse, sans pour autant que soit précisé avec qui et avec quels moyens. Toutes ces requêtes demeurent cependant vaines, la hiérarchie orthodoxe ne vouant qu'une confiance limitée à des prêtres parfois mutés en Asie centrale à la suite de sanctions diverses.

Le problème de la formation reste fondamental et est régulièrement évoqué : les missionnaires ne sont pas aptes à tenir une conversation avec les religieux musulmans ${ }^{44}$, ils ne parlent pas kazakh et n'ont qu'une connaissance rudimentaire de l'islam. L'Académie ecclésiastique de Kazan, unique institution chargée de former les missionnaires pour tout l'Orient russe, est elle aussi mise en cause, bon nombre de prêtres qui y ont été formés ayant renoncé à la mission ${ }^{45}$. L'enseignement dans cette Académie impose en effet l'apprentissage d'une langue ancienne, d'une langue européenne et de deux langues locales, programme considéré comme trop chargé pour permettre aux missionnaires de connaître de manière approfondie les langues locales. Demande est ainsi faite de créer un séminaire spécialisé pour les missionnaires envoyés dans les steppes kazakhes. Cette spécialisation impliquerait toutefois que le missionnaire restât en poste pour une longue période et qu'il ne soit pas régulièrement changé d'endroit. Le découragement des missionnaires a en effet entraîné de nombreux mouvements que l'on veut restreindre.

Si les missionnaires se plaignent des contrôles qu'exerce la hiérarchie religieuse, ils critiquent en revanche la rareté des visites de l'évêque, qui renforce leur sentiment d'isolement. Dans un deuxième temps, les missionnaires espèrent être aidés d'autres personnes chargées de fonctions précises : ils désirent, entre autres, envoyer dans les steppes des médecins dont ils pensent qu'ils ne susciteront pas de méfiance chez les Kazakhs. Ceux-ci auraient ainsi une double tâche, tant médicale que religieuse. Dans une même perspective, ils escomptent une aide des professeurs russes installés dans les villes kazakhes : ceux-ci, à l'instar des médecins, auraient pu, au travers de leur enseignement, servir la cause missionnaire de manière progressive et discrète afin que les autochtones ne réalisent pas la finalité de leur travail. Les missionnaires souhaitent enfin contourner le clivage homme/ femme, qui rend toute femme musulmane inaccessible au prosélytisme orthodoxe professé par des hommes, en demandant la formation de personnes de sexe féminin à cette fonction.

De leur côté, les prêtres paroissiens veulent conserver toutes leurs fonctions, tant vis-à-vis de la population coloniale que des autochtones convertis. Le baptême de

44. Les missionnaires sont confrontés aux mêmes problèmes avec les membres des différentes confessions protestantes qui ont une connaissance beaucoup plus précise de l'islam et des différences de dogme entre les cultes chrétiens.

45. Fondé en 1888 comme une section de l'Académie, l'Institut missionnaire de l'Académie de Kazan devient une institution indépendante en 1897. L'instruction y dure deux ans et n'est ouverte qu'à ceux qui ont déjà reçu une formation secondaire. 
ces derniers leur serait également confié. Une telle « séparation des pouvoirs » ne fait pas l'unanimité : elle est discutable au nom des écrits canoniques, nul pouvoir indépendant de l'évêque ne pouvant être formé dans une éparchie. Elle met également en cause des principes historiques jusque-là restés en vigueur : de nombreux chefs d'évêchés dirigent dans un même temps une mission, ce qui ne les a nullement empêchés d'obtenir des résultats probants. Refus est enfin donné à la proposition de mettre le chef de la mission sous le contrôle direct de l'évêque, ce qui aurait permis aux missionnaires d'adapter plus facilement leur travail aux conditions locales. La hiérarchie craint par une telle pratique que l'évêque ne s'occupe que de sa fonction missionnaire aux dépens de ses autres attributions. Une pléthore de suggestions sont ainsi avancées pour tenter de contourner les difficultés croissantes de la mission. La création d'un épiscopat missionnaire général est également soulevée mais considérée comme un bien maigre palliatif pour bon nombre de prêtres, qui ne voient pas comment on pourrait contrôler les stan-s isolés et situés très à l'écart de ce centre. La plupart des revendications des missionnaires restent donc lettre morte.

\section{Bilan chiffré et Congrès de Kazan}

Le bilan que les orthodoxes dressent de leur mission en ce début de siècle reste particulièrement pessimiste. Beaucoup ont perdu leurs illusions sur une œuvre à laquelle ils avaient pourtant aspiré depuis le début du siècle précédent. Le nombre de conversions de Kazakhs reste extrêmement limité : si on enregistre, en 1898 et 1902, 59 et 66 baptêmes, on passe à 22 conversions en 1905 et le chiffre ne cesse de diminuer à partir de $1906^{46}$. L'échec de la mission anti-musulmane est d'autant plus flagrant que celle de la partie orientale de la Russie se vante d'avoir amené à l'orthodoxie 15381 personnes, parmi lesquelles 6622 vieux-croyants, 1140 membres de sectes et quelque 3867 «païens » (chamanistes et Russes détachés de la religion) ${ }^{47}$. Stigmate d'un espoir révolu, le dépit pousse certains missionnaires à écrire dans leurs rapports que les Kazakhs viennent d'eux-mêmes embrasser le christianisme pour cacher au pouvoir l'extrême faiblesse de la mission ${ }^{48}$. L'édifice missionnaire qui avait été bâti sans que fussent établies au préalable de réelles fondations s'effondre donc de toutes parts. Face à cet échec croissant, le nombre de stan-s se réduit : quatre d'entre eux sont supprimés en 1906 et 1910 et, au lendemain de la loi de 1905, près de 12000 personnes abandonnent l'orthodoxie ${ }^{49}$.

46. Hiéromoine Feodorit, « O nuždah Kirgizskoj missii » (Au sujet des besoins de la mission kirghize), Missionerskij s"ezd v gorode Kazani, op. cit.

47. « Missionerskaja dejatel'nost' cerkvi (vtoraja polovina XIX-1917g.) » (L'activité missionnaire de l'Église (seconde moitié du XIX ${ }^{\mathrm{e}}$ siècle-1917), in A. I. Klibanov, Russkoe pravoslavie : Vehi istorii (L'orthodoxie russe : étapes de son histoire), Moscou, Politizdat, 1989, p. 439.

48. Missionerskij s"ezd v gorode Kazani, op. cit.

49. Plus de 4200 personnes retournent vers les mouvements vieux-croyants tandis que près de 5000 entrent dans des confessions considérées comme sectes. 
Au-delà de ce contexte général, chacun s'interroge sur les raisons de cet échec centrasiatique, mettant en parallèle les erreurs commises dans les steppes et celles de la Volga, et qui s'avèrent fatales pour les missions en territoire musulman. Ces interrogations sont tout particulièrement à l'ordre du jour lors du Congrès des missions orthodoxes en territoire musulman qui se tient à Kazan en 191050. Ce congrès permet une mise à plat des différents problèmes et révèle les très nombreuses divergences qui subsistent, tant entre les missionnaires et le clergé paroissial qu'entre le personnel religieux présent sur place et une hiérarchie orthodoxe ignorante des conditions locales. Les difficultés que rencontrent les missionnaires sur le terrain ont ainsi fait l'objet de longues discussions, sans pour autant aboutir à un accord permettant d'envisager une sérieuse réforme de la mission, que ce soit en pays tatar, au Caucase ou dans les steppes kazakhes. Seul subsiste un accord sur les finalités communes de la mission, à savoir une volonté d'amener les autochtones à la culture russe en vue d'une meilleure intégration.

Quelques mesures d'urgence sont cependant adoptées par le Synode en 1913, qui réunit l'ensemble des missions dans un seul et même centre, le Conseil missionnaire du Synode, dirigé par un de ses membres. Ce conseil doit convoquer de manière régulière des congrès missionnaires nationaux et locaux, organiser des cours à destination des missionnaires et gérer de manière générale tous les aspects des missions, en particulier les méthodes de lutte contre les autres religions et les mouvements dits sectaires ${ }^{51}$. Enfin, du 26 juin au 4 août 1917, se tient dans le gouvernorat de Kherson le Ve Congrès missionnaire, au cours duquel on tente de resserrer les liens entre prêtres et missionnaires et d'impliquer le clergé monastique dans l'effort missionnaire. La Première Guerre mondiale ainsi que les tournants de l'année 1917 empêcheront tant le Conseil missionnaire que ce congrès d'aboutir à des résultats concrets.

Le dépit parmi le clergé et les prosélytes est tel en ce début de siècle que ceux-ci analysent leur isolement comme une mise à l'écart définitive. Délaissés par des autorités peu soucieuses de leurs projets, ils perçoivent des attaques de toutes parts, tant des mouvements chrétiens dits sectaires que des musulmans. La nécessité d'isoler les nouveaux convertis dans des villages réservés et peuplés de Russes reste peu réalisable compte tenu des nombreuses restrictions mentionnées. Sur les quelque 800 baptêmes enregistrés depuis la création de la mission en 1883, au moins 200 personnes ont apostasié, surtout après la loi de 1905. Enfin, les missionnaires estiment que les chrétiens eux-mêmes sont sous la menace de l'influence musulmane : plusieurs cas de conversions de Russes ou de personnes d'origine européenne à l'islam sont rapportés ${ }^{52}$. D'une stratégie offensive à l'égard de l'islam, proposée lors de longues négociations avec les autorités au cours du

50. Les actes du congrès sont publiés un an plus tard sous le titre de Missionerskij s"ezd V gorode Kazani (Le Congrès missionnaire dans la ville de Kazan), op. cit. Sur ce congrès, on pourra également consulter F. T. McCarthy, « The Kazan Missionary Congress », art. cit., ainsi que « Kazanskij missionerskij s"'ezd », art. cit., p. 304-305.

51. Le Conseil publie un journal à partir de 1916, Cerkovnyj vestnik.

52. Voir Turkestanskie eparhial'nye vedomosti, 15, 1913, p. 323-338. 
$\mathrm{XIX}^{\mathrm{e}}$ siècle, l'Église est désormais passée à une tactique défensive qui consiste autant à protéger la communauté chrétienne - tant coloniale que celle des Kazakhs convertis - qu'à promouvoir une politique de conversion parmi les autochtones. Les hésitations que montrent les missionnaires dans leur politique d'approche sont de fait en partie réglées par un contexte de torpeur et d'impuissance qui rend impossible tout exercice d'une réelle politique missionnaire.

Les échecs répétés de la mission ne remettent cependant pas en cause le projet missionnaire dans son ensemble, y compris en Asie centrale, puisque les autorités religieuses continuent à demander l'ouverture d'une mission dans le gouvernorat du Turkestan. La conquête plus tardive de cette région, une population beaucoup plus islamisée que dans les steppes et enfin l'insuccès confirmé de la mission kirghize conduisent les autorités à opposer un refus systématique à ces nombreuses demandes. Les prêtres missionnaires agissent donc pendant plusieurs années dans un cadre semi-officiel ; quelques-uns tentent de convertir des musulmans en diffusant des ouvrages religieux avant même que ne soit établie une structure missionnaire. Les autorités autorisent toutefois le missionnariat auprès des populations immigrées d'origine chinoise, les Dounganes, ainsi qu'auprès des Ouïgours ${ }^{53}$. Une mission est finalement ouverte à Tachkent en août 191254, dont les méthodes témoignent tant de l'insuccès de la mission kirghize que d'un environnement musulman beaucoup plus marqué et qu'il est indispensable de prendre en considération. Cette mission prend ainsi un aspect beaucoup moins offensif - on se refuse à toute critique du Coran - et aboutit à des résultats dérisoires - quelques conversions seulement - jusqu'à sa suppression après la révolution bolchevique.

Au terme de plus de trente années de missions dans les steppes kazakhes, l'échec orthodoxe est flagrant et s'explique dans le cadre d'une triangulaire colonisateurcolonisé-gouvernement. L'empire a paradoxalement peu fait pour la christianisation des allogènes kazakhs et les missionnaires orthodoxes se sont révélés inadaptés à leur environnement, écrasés par une hostilité venant de toutes parts, tant du côté du «clergé » de l'islam, des Kazakhs, musulmans ou chamanistes, que du côté du pouvoir, de la hiérarchie religieuse et des colons russes eux-mêmes. Les raisons de l'échec doivent donc être recherchées non seulement dans le contexte minoritaire des colons et des chrétiens mais également dans la perte d'influence d'une Église rejetée des hautes sphères du pouvoir. Ainsi, les difficultés des missions orthodoxes entrent davantage dans un cadre interne au monde russe que dans celui d'un débat théologique interreligieux, aussi complexe soit-il. L'histoire de la «mission

53. Venus de Chine dans les années 1860, ces populations se sont essentiellement installées dans l'oblast' du Semirečé. Les orthodoxes ont, dès les premiers temps, concentré leurs efforts sur cette communauté. L'Église avance que, dès 1872, 700 immigrés chinois ont été convertis, un chiffre à prendre avec beaucoup de réserve. Sur ce sujet, «Kitajskie emigranty v semireč'enskoj oblasti turkestanskogo kraja i rasprostranenie sredi nih pravoslavnogo hristianstva » (Les émigrés chinois dans l'oblast' de Semireč'e du territoire du Turkestan et la propagation parmi eux du christianisme orthodoxe), Pravoslavnyj sobesednik, 2, 1879, p. 228.

54. «Učreždenie protivomusul'manskoj missii v Turkestanskoj eparhii » (La fondation de la mission anti-musulmane du diocèse du Turkestan), Turkestanskie eparhial'nye vedomosti, 17, 1913, p. 384-400. 
kirghize anti-musulmane » en territoire kazakh au XIX ${ }^{\mathrm{e}}$ siècle peut également être mise en parallèle avec la situation religieuse du Kazakhstan indépendant contemporain $^{55}$. Si les conditions politiques et socio-économiques actuelles sont très différentes de celles du siècle précédent, l'Église orthodoxe doit de nouveau apprendre à vivre son caractère minoritaire à l'heure où les Russes et les populations slaves et européennes quittent en grand nombre l'ensemble de l'Asie centrale. Elle doit également gérer une situation de non-monopole et de liberté religieuse face à la progression d'un islam qui se veut religion « nationale » des Kazakhs et au considérable développement des mouvements protestants et catholique dans la zone.

\section{Institut français d'études sur l'Asie centrale}

Tachkent

sebpeyrouse@yahoo.com

55. Sur le christianisme en Asie centrale contemporaine, voir S. Peyrouse, Des chrétiens entre athéisme et islam : regards sur la question religieuse en Asie centrale soviétique et post-soviétique. Préf. de Patrick Michel, Paris, Maisonneuve et Larose - Institut français d'études sur 1'Asie centrale, 2003, 406 p. 